\title{
An Approximate Method of Determining the Velocity Gradient in Spiral Flocculation
}

$$
\text { طريقة تقريبية لحساب أنحار السرعة في الترويب الحلزوني }
$$

Ahamed Fadel Ashery', Kamal Radwan², and Mohamed I. Gar Al-Alm Rashed ${ }^{3}$.

${ }^{1}$ Public Works Department, Faculty of Engineering - Mansoura University

${ }^{2}$ Public Works Department, Faculty of Engineering - Mansoura University, dr_kamal15@yahoo.com

${ }^{3}$ Public Works Cepartment, Faculty of Engineering - Mansoura University, m_gar_alalm@yahoo.com

\section{مان}

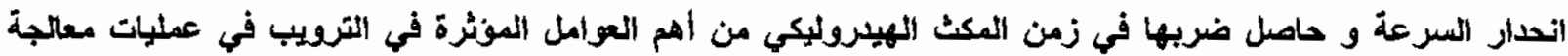

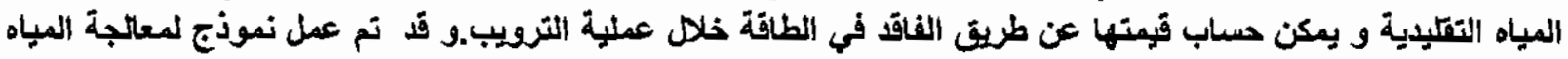

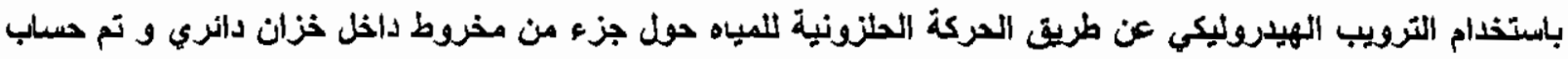

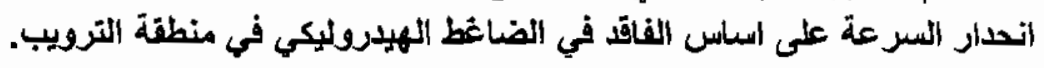

\section{Abstract}

The velocity gradient (G-value) and the value of GT are highly correlated to the flocculation efficiency in conventional water treatment process. The determination of $G$-value is always related to the energy dissipated in flocculation zone. Hydraulic flocculation was established by high speed tangential inlet flow in circular tank with internal cone which give spiral movement of water between the inner surface of the tank and the outer surface of the cone. This work gives an approximate determination of the variation velocity gradient in the flocculation process by calculating the energy dissipated in fiocculation on the basis of the head loss through flocculation zone.

Keywords: Velocity gradient, Hydraulic flocculation, spiral

\section{Introduction}

Flocculation, coagulation, and sedimentation have become important unit processes in the treatment of water and wastewater in conjunction with conventional mechanical, biological and physicochemical plants.(Vigenswaran and Setiadi, 1985; Liu et al, 2003; Yang et al, 2010; Thiruvenkatacinari, et al, 2002)

Hydraulic flocculation have been used for water treatment in many countries with design based on the intensity of energy dissipation in the system usually related to ensuring that a particular value of average shear rate or velocity gradient, $G$, or the product of velocity gradient and retention time, GT, is attained (Mcconnachie and Liu, 1990; Su et al ,2003). For successful flocculation the value of $G$ value suggested to range from 10 to $100 \mathrm{sec}^{-1}$ reducing progressively in discrete stages "tapered flocculation" and GT was to be within the limits of $10^{4} 10^{5}$. These values have normally been adopted by designers to date (Mcconnachie and Liu, 1990). The main 
C. 51 Ahamed Fadel Ashery, Kamal Radwan and Mohamed I. Gar Al-Alm Rashed.

design issue for hydraulic flocculators is ehether there is head available in the plant profile to provide the required power input. Hydraulic flocculators often operate well at low flow conditions even if average velocity gradient is as low as $10 \mathrm{sec}^{-1}$, because the longer detention time still provides for an adequate GT value (Kawamura, 2000; Crittenden, et al, 2005).

The velocity gradient value is always calculated based on the intensity of energy dissipation in the flocculation area and usually related to the average viscous shear and the standard expression of velocity gradient is given by equation (1).

$$
G=\sqrt{\frac{P}{\mu V}}
$$

where $P$ is the power dissipated in fluid motion, $\mu$ is the dynamic viscosity of the water and $V$ is the volume of water in the flocculation zone. For the work done by the water flowing through a focculator where head loss is involved.

$P=\rho g Q \Delta H$

where $\rho$ is the water density, $\mathrm{g}$ is the gravitationai constant, $Q$ is the volumetric rate of flow and $\Delta \mathrm{H}$ is the total head loss over the flocculation zone under consideration. Combining equations. (1) and (2) gives

$$
G=\sqrt{\frac{\rho g Q \Delta H}{\mu V}}
$$

The head loss resulting due to water movement in flocculation zone is a function of the velocity of the water and could be calculated by equation (4)

$$
\Delta H=\frac{k v^{2}}{2 g}
$$

Where $k$ is an empirical constant which ranges from 2.4 to 4.0 in baffled flocculation (Mcconnachie and Liu, 1990; Monk and Trussell, 1991; Vigenswaran and Setiadi, 1985). No referenced values for the constant $\mathrm{k}$ in spiral hydraulic flocculation are issued in earlier researches.

\section{Materials and Methods}

\subsection{System components}

The main objective of the proposed system is to deliver the synthetic turbid water to the clari-flocculation basin after rapid mixing with coagulant solution. A combination of mechanical and hydraulic equipments is used to establish a complete system to deliver turbid water and coagulant solution and drive it to the treating basin as shown in Fig (1). This system is composed of the following component:

Feeding tank A 200-liter plastic tank used to storage the synthetic turbid water equipped with a mechanical stirrer to prevent sedimentation and change of initial properties of synthetic water like turbidity and NOM concentration. The mechanical stirrer also keep the homogeneity of the synthetic water among the different levels of the tank. The feeding tank is provided with a valve to control the discharge to the treating basin. The circular wall of tank is provide with volumetric scale to facilitate the measuring of discharge of turbid water going out to the clari-flocculator basin. 


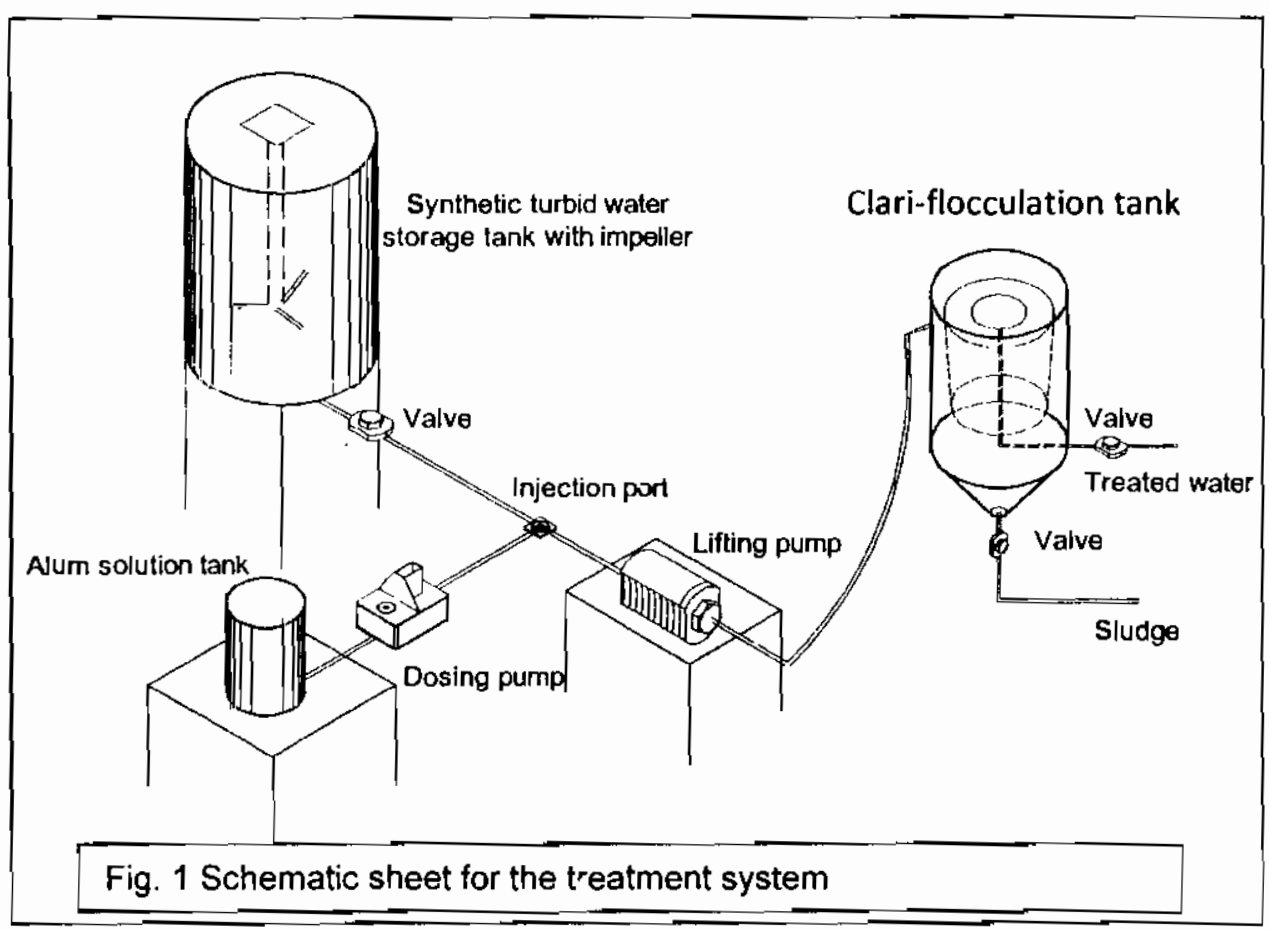

Coagulant feed tank A 20 liter plastic tank contains the coagulant solution and provided manually. This tank is directly connected to the drag side of a dosing pump.

Dosing pump A pump with a variable scaled speed to control the coagulant dose delivered to the clari-flocculator basin. The drag side is submerged into the coagulant feed tank, while the outlet side is connected to an injection port in the path of the raw water came from the feeding tank and placed previous to the lifting pump.

Lifting pump it is a centrifugal pump equipped with an impeller in which turbid water, coagulants are vigorously mixed, and it is responsible for lifting and delivering the synthetic water mixed with coagulant solution to the treating basin.

Turbidity material: Synthetic turbid waters were prepared by using kaolinite particles take the form of pseudo-hexagonai platelets with widths that vary from 10 to $0.1 \mu \mathrm{m}$ and less, with a chemical structure $\underline{\mathrm{Al}}_{2} \mathrm{Si}_{2} \underline{\mathrm{O}}_{5}(\underline{\mathrm{OH}})_{4}$, as supplied from AlGomhoria Co for Chemicals (Egypt).

Turbiditymeter: To measure the turbidity (Hanna turbiditymeter HI93703) was used with $10 \mathrm{~mm}$ cell.

Hydraulic clari-flocculation basin The Clari-flocculator is hydraulic, and the outer structure is a stainless steel cylinder with diameter $600 \mathrm{~mm}$, and the bottom is a cone with $150 \mathrm{~mm}$ height as shown in Fig (2). The inner structure is composed of stainless steel removable frustum of cone. In order to investigate the effect of shape and volumetric changes of different treating processes including in this basin two frustums of cones are provided with different configuration as shown in Fig (3).

The water get into the basin through a copper jet perpendicular to the tangent line at the inlet point. The jet provides high 


\section{53 Ahamed Fadel Ashery, Kamal Radwan and Mohamed I. Gar Al-Alm Rashed.}

tangential water speed at the inlet which generate helical (spiral) path for the water in the space outer the cone. This spiral path of water around the inner cone constitutes the flocculation process. The velocity path couid be analyzed in two derivatives downwards vertical vector and tangential vector. In both vectors the velocity is decreases uniformly. The downwards vertical velocity is come out from the overall discharge divided on the horizontal cross-area, which equal the horizontal cross-area of cone at certain level subtracted from the horizontal cross-area of the outer body of the basin. The horizontal cross-area of cone decreases uniformly so the net horizontal cross area increases, and while the discharge is fixed the vertical velocity decreases uniformly. The tangential path comes out from the water tangential speed at the inlet jet. The tangential water velocity decreases uniformly as a result of the friction with the walls of the basin and cone, and the friction between water layers.
As a result of the decreasing velocity of vertical and tangential water paths, the velocity gradient of water at the flocculation zone is considered to be a very differential uniform velocity gradient. This gives a suitable condition for flocculation process if it takes its preferred retention time.

The inner cone is the major space of sedimentation zone. It delivers the water from the lower part of flocculation zone then the water go upwards through the cone while the floccs formed during the flocculation process are settled by gravity, and small particles may induce a blanket clarification process. $V$ notch weirs of the collector plate collect the clarified water at the upper level of cone and transfer it to the outlet pipe

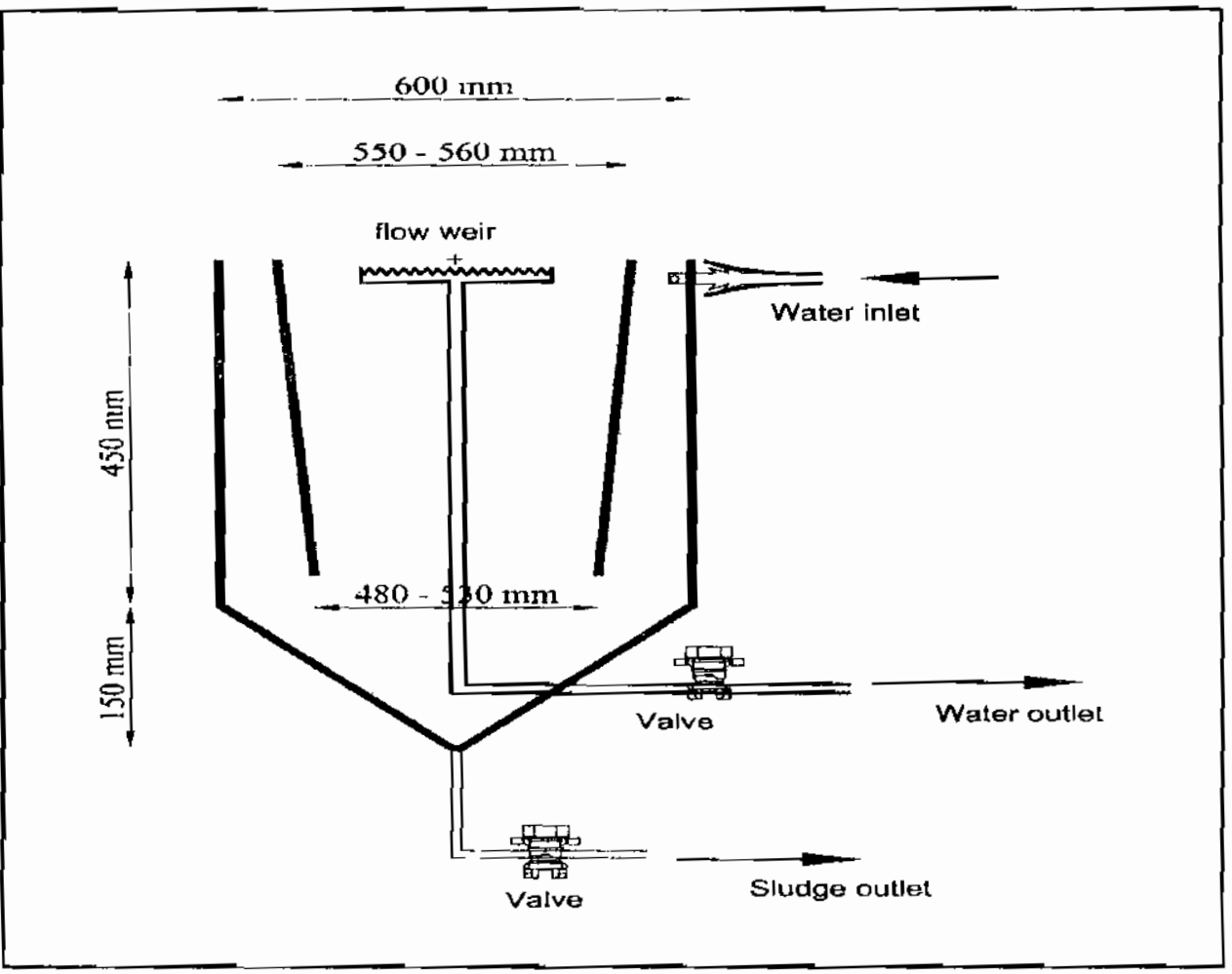

Fig.2 The treatment tank configuration 


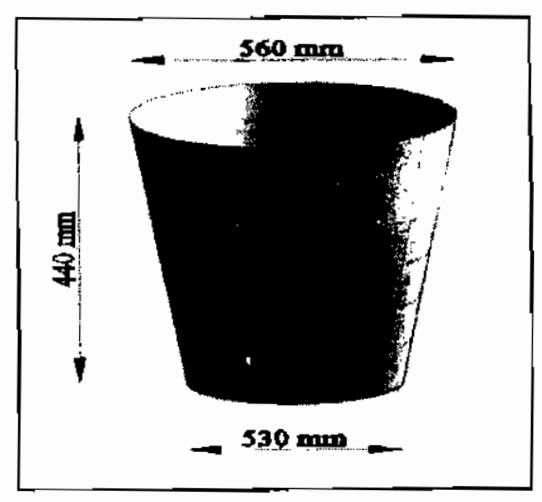

Cone 1
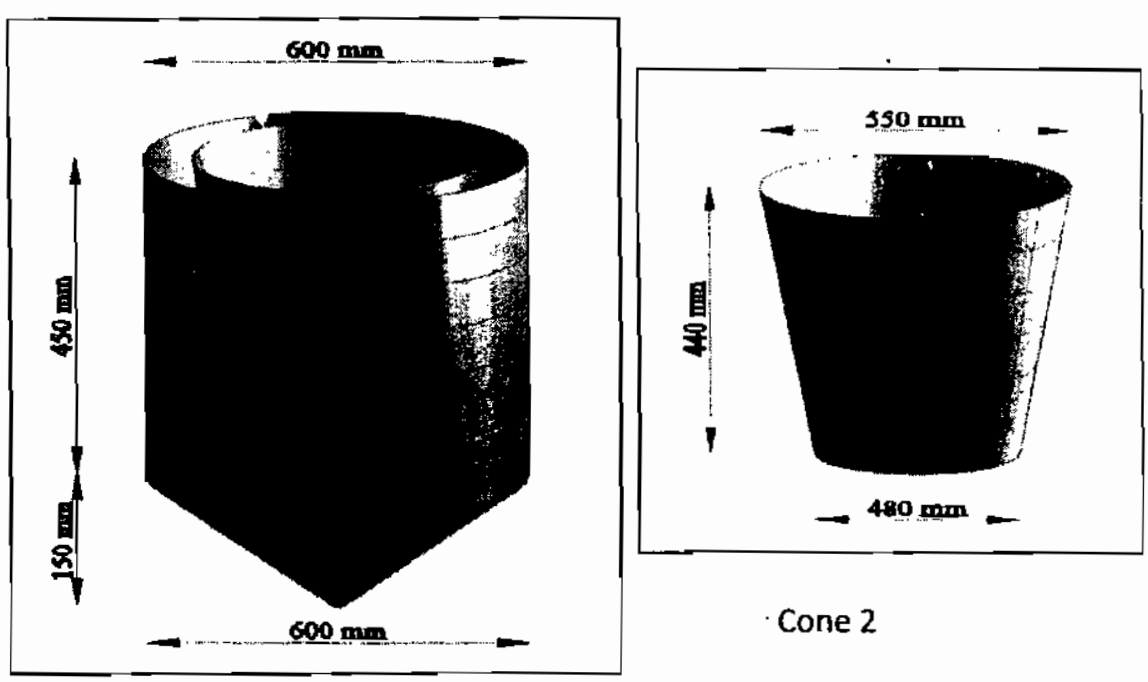

Cone 2

Fig .3 perspestive treatment tank dimensions

\subsection{Experimental procedure}

The lift pump to carry the water from the feeding tank to the flocculation tank. The discharge of raw water is controlled by a vaive at the outlet of the feed tank and computed on the basis of the retention time of the flocculation and sedimentation process and the volume of the flocculation zone and sedimentation zone as illustrated in table (1) and table (2).

For each run the instant velocity at water surface was approximately determined by the average time of fluid over specified distance using a dye of methyl orange.

Table (1) The Dimensions of the basin

\begin{tabular}{|c|r|c|}
\hline & cone 1 & cone 2 \\
\hline Dimensions (mm) & $560 \times 530 \times 440$ & $550 \times 480 \times 440$ \\
$D_{1} \times D_{2} \times \mathrm{h}$ & & \\
\hline Flocculation zone (Lit) & 22.23 & 33.35 \\
\hline Sedimentation Zone (Lit) & 120.15 & 109.03 \\
\hline Total Volume (Lit) & 142.38 & \\
\hline
\end{tabular}




\section{55 Ahamed Fadel Ashery, Kamal Radwan and Mohamed I. Gar Al-Alm Rashed.}

Table (2) The operation parameters of the system

\begin{tabular}{|c|c|c|c|c|}
\hline & $\begin{array}{c}\text { Flocculation time } \\
\text { (minute) }\end{array}$ & $\begin{array}{c}\text { Sedimentation time } \\
\text { (minute) }\end{array}$ & $\begin{array}{c}\text { Total retention time } \\
\text { (minute) }\end{array}$ & Discharge (Lit/minute) \\
\hline \multirow{2}{*}{ cone 1 } & 15 & 81 & 96 & 1.48 \\
\cline { 2 - 5 } & 20 & 108 & 160 & 1.11 \\
\hline & 25 & 135 & 192 & 0.89 \\
\hline \multirow{2}{*}{ cone 2 } & 30 & 162 & 64 & 0.74 \\
\hline & 15 & 49 & 86 & 2.22 \\
\hline
\end{tabular}

\section{Results and Discussion.}

\subsection{Velocity gradient calculations.}

As discussed before, the velocity gradient is a function in energy dissipated through the flocculation zone. In hydraulic flocculation the energy dissipated could be expressed by the head loss of water during flocculation process which calculated by equation (4) and assume that the constant $k=1$.

If the equation (3) applied to the total volume of flocculation zone the G-value obtained will be the average velocity gradient over flocculation process. In order to obtain the variability of G-value, the flocculation zone was divided into four sections with equal depth and the volume of each section has been calculated by subtracting the volume of frustum of cone from the volume of cylinder with depth equal the quarter of the depth of flocculation zone. While the velocity in the beginning of each section $v_{1}$ and the end limit $v_{2}$ of each section were calculated by assuming that velocity distribution will be approximately linear. If the velocity at upper surface is equal $v_{\text {initial }}$ the beginning velocity $v_{1}$ for $1^{\text {st }}$, $2^{\text {nd }}, 3^{\text {rd }}, 4^{\text {th }}$, sections will be $v_{\text {iniliai }}, 0.75$ $v_{\text {inilial, }} 0.5 \mathrm{v}_{\text {inilial, }}$, and $0.25 \mathrm{v}_{\text {initial }}$ respectively, while the end limit velocity $v_{2}$ will be 0.75 $v_{\text {initial, }} 0.5 v_{\text {initial, }} 0.25 v_{\text {initial }}$, and zero respectively, then the head loss could be calculated according to equation (5) for each section.

$\Delta H=\frac{\theta_{1}^{2}-\theta_{2}^{2}}{2 g}$

For average velocity gradient calculation $v_{1}$ is the surface velocity of water in the flocculation zone and $v_{2}$ is the velocity at the lower portion of flocculation zone. The velocity of water in the lower portion where the water begin to deviate from the downwards spiral path to upwards path in the cone zone is assumed to be neglected then the value of head loss could be 
calculated according to the upper surface velocity.

The upper surface velocity is formed by the very high shooting speed from the water jet nozzle at the inlet which dissipates high energy in a very short time which enharices mixing. After a short length the water speed will assumed to have a regular variability, and could be measured. The instant velocity at water surface was approximately determined by the average time of fluid over specified distance using a dye of methyl orange.
The calculations of velocity gradient are illustrated in tables (3) and (4) showing the average velocity gradient and the variability of velocity gradient along the flocculation depth for each run of experiment. The values of GT are obtained based on average G-values. The variability of velocity gradient for all discharge values is shown in Figs (4) and (5) which clarify that the velocity gradient is almost decreasing when the flow go down in flocculation zone with a rate could be considered uniform decreasing rate.

Table. 3 Velocity gradient calculation for cone 1

\begin{tabular}{|c|c|c|c|c|c|c|}
\hline $\begin{array}{l}\text { Discharge (Lit } \\
\text { /min) }\end{array}$ & $\begin{array}{c}\text { Initial velocity } \\
(\mathrm{m} / \mathrm{s})\end{array}$ & Section & Head loss $(m)$ & $\begin{array}{c}\text { Section } \\
\text { volume (Lit) }\end{array}$ & $\begin{array}{c}\text { Velocity } \\
\text { gradient }\left(\sec ^{-1}\right)\end{array}$ & $\mathrm{G}_{\mathrm{er}} \mathrm{T}$ \\
\hline 1.48 & 0.75 & $\begin{array}{c}1 \\
2 \\
3 \\
4 \\
\text { overaly }\end{array}$ & $\begin{array}{l}0.0125 \\
0.0090 \\
0.0054 \\
0.0018 \\
0.0 \% 87\end{array}$ & \begin{tabular}{|c|}
4.368 \\
5.048 \\
5.79 \\
6.487 \\
2273
\end{tabular} & $\begin{array}{c}26.33 \\
20.70 \\
14.97 \\
8.17 \\
17.65\end{array}$ & 15885 \\
\hline 1.11 & 0.63 & $\begin{array}{c}1 \\
2 \\
3 \\
4 \\
\text { oreraty }\end{array}$ & $\begin{array}{l}0.0089 \\
0.0063 \\
0.0038 \\
0.0013 \\
0.0 \% 02\end{array}$ & \begin{tabular}{|c|}
4.368 \\
5.048 \\
5.79 \\
6.487 \\
22.23
\end{tabular} & $\begin{array}{c}19.16 \\
15.06 \\
10.89 \\
5.94 \\
12.84\end{array}$ & 15408 \\
\hline 0.89 & 0.54 & \begin{tabular}{|c|} 
\\
2 \\
3 \\
4 \\
Overal
\end{tabular} & $\begin{array}{l}0.0065 \\
0.0046 \\
0.0028 \\
0.0009 \\
0.0149\end{array}$ & \begin{tabular}{|c|}
4.368 \\
5.048 \\
5.79 \\
6.487 \\
22.23
\end{tabular} & $\begin{array}{r}14.70 \\
11.56 \\
8.36 \\
4.56 \\
9.85\end{array}$ & 14775 \\
\hline 0.74 & 0.43 & $\begin{array}{c}1 \\
2 \\
3 \\
4 \\
\text { Overail }\end{array}$ & $\begin{array}{l}0.0041 \\
0.0029 \\
0.0018 \\
0.0006 \\
0.0094\end{array}$ & \begin{tabular}{|c|}
4.368 \\
5.048 \\
5.79 \\
6.487 \\
22.23 \\
\end{tabular} & $\begin{array}{c}10.68 \\
8.39 \\
6.07 \\
3.31 \\
7.15\end{array}$ & 12870 \\
\hline
\end{tabular}


C. 57 Ahamed Fadel Ashery, Kamal Radwan and Mohamed I. Gar Al-Alm Rashed.

Table. 4 Velocity gradient calculation for cone 2

\begin{tabular}{|c|c|c|c|c|c|c|}
\hline $\begin{array}{c}\text { Discharge (Lit } \\
/ \mathrm{min})\end{array}$ & $\begin{array}{l}\text { Initial velocity } \\
(\mathrm{m} / \mathrm{s})\end{array}$ & Section & Head loss (m) & $\begin{array}{c}\text { Section } \\
\text { volume (Lit) }\end{array}$ & $\begin{array}{c}\text { Velocity } \\
\text { gradient }\left(\mathrm{sec}^{-1}\right)\end{array}$ & $G_{e v} T$ \\
\hline 2.22 & 0.81 & $\begin{array}{c}1 \\
2 \\
3 \\
4 \\
\text { Overall }\end{array}$ & $\begin{array}{l}0.0146 \\
0.0105 \\
0.0063 \\
0.0021 \\
0.0334\end{array}$ & \begin{tabular}{|l|}
5.789 \\
7.399 \\
8.956 \\
10.46 \\
33.35 \\
\end{tabular} & $\begin{array}{r}30.26 \\
22.62 \\
15.93 \\
8.51 \\
19.06\end{array}$ & 17154 \\
\hline 1.67 & 0.69 & $\begin{array}{c}1 \\
2 \\
3 \\
4 \\
\text { Overal }\end{array}$ & \begin{tabular}{|l|}
0.0106 \\
0.0076 \\
0.0045 \\
0.0015 \\
0.0243
\end{tabular} & $\begin{array}{l}5.789 \\
7.399 \\
8.956 \\
10.46 \\
33.35\end{array}$ & \begin{tabular}{|c|}
22.35 \\
16.71 \\
11.77 \\
6.29 \\
14.08 \\
\end{tabular} & 16896 \\
\hline 1.33 & 0.58 & $\begin{array}{c}1 \\
2 \\
3 \\
4 \\
\text { Overall }\end{array}$ & $\begin{array}{l}0.0075 \\
0.0054 \\
0.0032 \\
0.0011 \\
0.0171\end{array}$ & $\begin{array}{l}5.789 \\
7.399 \\
8.956 \\
10.46 \\
33.35 \\
\end{array}$ & $\begin{array}{r}16.77 \\
12.54 \\
8.83 \\
4.72 \\
10.56\end{array}$ & 15975 \\
\hline 1.11 & 0.50 & \begin{tabular}{|c|}
1 \\
2 \\
3 \\
4 \\
Overal
\end{tabular} & $\begin{array}{c}0.0056 \\
0.0040 \\
0.0024 \\
0.0008 \\
0.0121\end{array}$ & $\begin{array}{r}5.789 \\
7.399 \\
8.956 \\
10.46 \\
33.35\end{array}$ & $\begin{array}{l}13.21 \\
9.87 \\
6.95 \\
3.71 \\
8.32\end{array}$ & 14976 \\
\hline
\end{tabular}

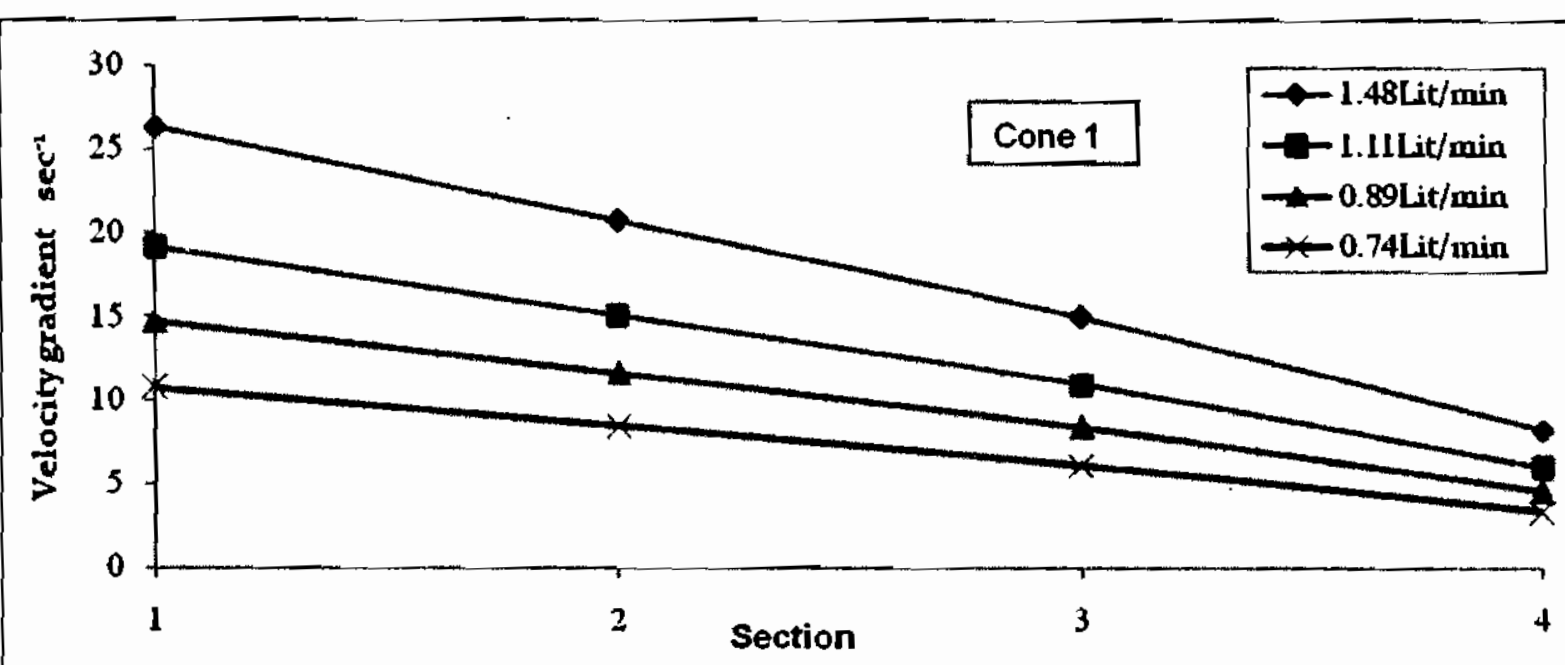

Fig. 4 The variation of velocity gradient over the flocculator depth for cone 1 


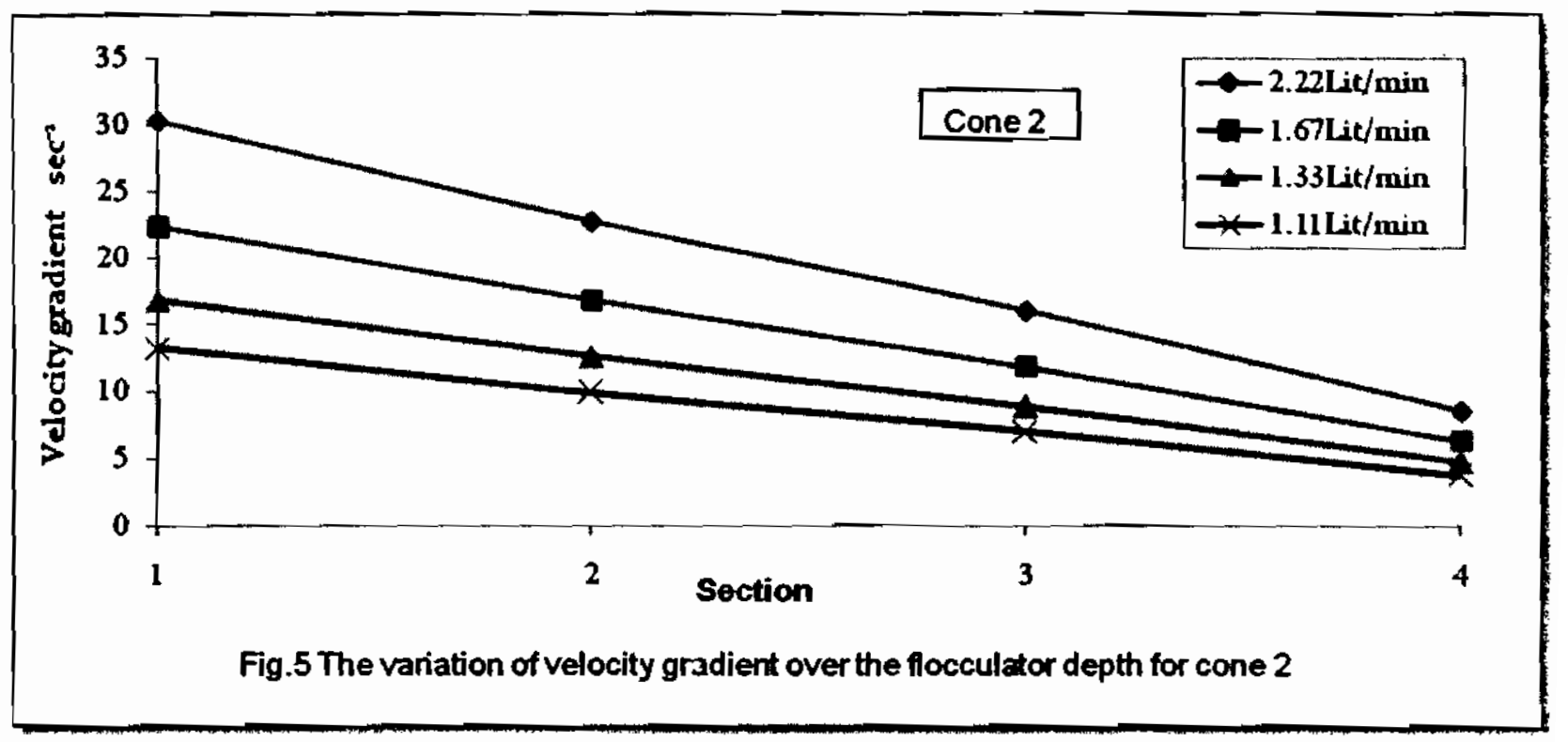

The average values of velocity gradient are highly affected by the discharge and retention time, that because the initial velocity at the upper surface of water in flocculation zone is depend on the discharge coming from the inlet jet., For that reason cone 2 gives an average velocity gradient higher than cone 1 as the discharges of cone 2 are higher as shown in table 2. On the other hand the dimensions of cone 1 give more suitable decreasing rate of velocity gradient because the diameter of the cone doesn't decrease rapidly, while the diameter of cone 2 decreases sharply so the volumes of sections are increasing consecutively, which decreases the velocity gradient faster than cone1.

\subsection{Turbidity removal}

The capability of flocculation and sedimentation processes in turbidity removal by this system was investigated by using two different synthetic turbid water with about 30 NTU for the lower turbidity water and 130 NTU for the higher one. The $\mathrm{pH}$ of both synthetic turbid waters was about 7 . The coagulant dose used was the optimum dose determined according to the jar tests carried out as shown in bench scale studies which was $45 \mathrm{mg} / \mathrm{l}$ for high turbidity water and $25 \mathrm{mg} / \mathrm{l}$ for low turbidity water. The tests was performed by using the two cones to separate and form the flocculation and sedimentation zones as calculated in table (1). The G-values of these tests could not be controlled to be a fixed parameter for all operation because it changes according to both of discharge and the dimension of the cone inserted in the system. 
C. 59 Ahamed Fadel Ashery, Kamal Radwan and Mohamed I. Gar Al-Alm Rashed.
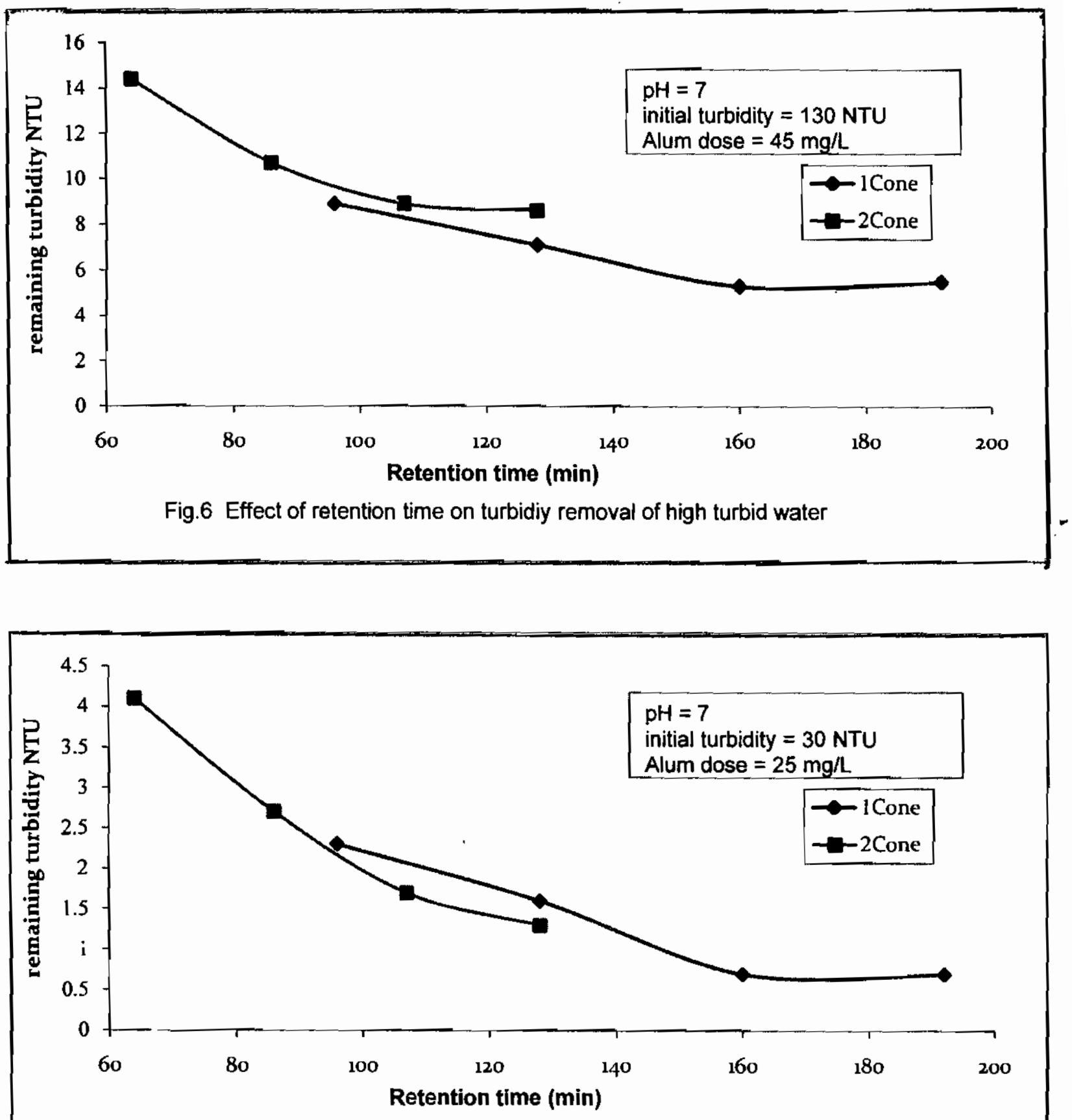

Fig.7 Effect of retention time on turbidiy removal of low turbid water

As illustrated in Fig (6) the best turbidity removal by cone 1 was at overall retention time of 160 minute composed of 25 minute for flocculation process and 135 minute for sedimentation process leaving out about 5.3
NTU as remaining turbidity on average. When retention time was raised to 192 minute composed of 30 minute for flocculation process and 162 minute for sedimentation process the remaining 
turbidity measured was not significantly changed and it was 5.5 NTU on average. For cone 2 it was investigated that best removal efficiency was indicated when the retention time was about 128 minute composed of 30 minute for flocculation process and 98 minute for sedimentation process leaving out about 8.6 NTU as remaining turbidity on average. For any runs on cone 2 the longer retention time the better removal was indicated as shown in Fig (6).

For low turbidity water, the best turbidity removal when using cone 1 was indicated at overall retention time of 160 minute composed of 25 minute for flocculation process and 135 minute for sedimentation process as shown in Fig (7) leaving out about 0.7 NTU as remaining turbidity on average. Rising the overall retention time to 192 minute composed of 30 minute for flocculation process and 162 minute for sedimentation process did not give significant change in the remaining turbidity as it was about 0.7 NTU on average. For cone 2 the longer retention time the better removal was indicated as shown in Fig (7), so the best removal was indicated when the retention time was 128 minute composed of 30 minute for flocculation process and 98 minute for sedimentation process leaving out about 1.3 NTU as remaining turbidity on average.

The obtained results clarify that the configuration of the clarifier model when using cone 1 is more better than the configuration when using cone 2 . better turbidity. The geometric configuration of the model when using cone 1 gives the opportunity to suitable retention times of both flocculation and sedimentation process.

\section{Conclusion}

1. The values of velocity gradient in spiral hydraulic flocculation could be determined on the basis of energy dissipated by calculating the head loss in flocculation zone.

2. The hydraulic flocculation with the studied system could achieve a suitable velocity gradient to be sufficient for flocculation process.

3. The studied system give a very uniform tapered flocculation because the velocity gradient is decreasing very smooth through the flocculation zone.

4. All the discharges illustrated in table (2) could achieve effective flocculation in conventional water treatment because the values of GT are always higher than 10000 .

5. The best turbidity removal was at retention time of 160 minute either using cone 1 or cone 2 .

\section{References}

Crittenden, J. C., Trussell, R. R., Hand, D. W., Howe, K. J., Tchobanoglous, G. (2005)'Water Treatment: Principles and Design" Jhon Wiley \& Sons, Inc. 758-762.

Kawamura, s (2000) Integrated design and operation of water treatment facilities, 2nd edition., Willy-Interscience, New York. 


\section{61 Ahamed Fadel Ashery, Kamal Radwan and Mohamed I. Gar Al-Alm Rashed.}

Kawamura, s (2000) Integrated design and operation of water treatment facilities, 2nd edition., Willy-Interscience, New York.

Liu, J., Crapper, M., McConnachie, G.L. (2003) "An accurate approach to the design of channel hydraulic flocculators". Water Res. 38 pp. 875-886.

McConnachie, G.L., Liu, J. (1999) "Design of baffled hydraulic channels for turbulence induced flocculation." Wat. Res. 34, pp. 1886-1896.

Monk, R., and Trussell, R. (1991) "Design of mixers for water treatment plants: Rapid mixing and flocculators, in mixing in coagulation and flocculation", in A.Amirtharajah, M.Clarck, and R. Trussell (eds.), American Water Works Association Research Foundation, Denver, CO, pp. 380419.

Rossini, m., Garcia Garrido, J., and Galluzzo, M. (1998) "Optimization of the coagulationflocculation treatment: Influence of rapid mix parameters.", Wat. Res. 33, pp. 1817-1826.

Thiruvenkatachari, R., Ngo, H. H, Hagare, P., Vigneswaran, S. Ben Aim, R. (2002) "Flocculation-cross-flow microfiltration hybrid system for natural organic matter (NOM) removal using hematite as a flocculent" Desalination 147 83-88.

Yang, Z. L.: Gao, B Y, Yue, Q. Y, Wang, Y. (2010) "Effect of $\mathrm{pH}$ on the coagulation performance of Al-based coagulants and residual aluminum speciation during the treatment of humic acid-kaolin synthetic water" Journal of Hazardous Material. 